\title{
INVESTIGATIONS ON THE SURFACE ROUGHNESS PRODUCED IN TURNING OF AL6061 (AS-CAST) BY TAGUCHI METHOD
}

\author{
Deepak $\mathrm{D}^{1}$, Rajendra $\mathrm{B}^{2}$

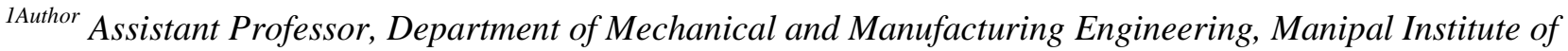 \\ Technology, Manipal University, Manipal -576104, India. \\ nie.deepak@gmail.com \\ ${ }^{2 C o r r e s p o n d i n g ~ A u t h o r ~ P r o f e s s o r, ~ D e p a r t m e n t ~ o f ~ M e c h a n i c a l ~ a n d ~ M a n u f a c t u r i n g ~ E n g i n e e r i n g, ~ M a n i p a l ~ I n s t i t u t e ~ o f ~}$ \\ Technology, Manipal University, Manipal -576104, India. \\ rajbeedu@yahoo.co.in
}

\begin{abstract}
:
Surface roughness produced on the machined component is one of the key attribute of machining process. In this work the effect of various turning process parameters on surface roughness produced on Al6061 (as cast condition) is investigated. Also the effect of using coolant on surface roughness while turning is also determined. It is observed increase in cutting speed by 39.29\% resulted in decrease of surface roughness by $31.44 \%$. Increase in feed rate and depth of cut leads to increase in surface roughness. Quantitative analysis of surface roughness obtained in machining with coolant and without coolant is also presented.
\end{abstract}

Keywords: Al6061, Surface Roughness, Turning Process, Spindle Speed, Depth of Cut, ANOVA

\section{INTRODUCTION}

ALUMINIUM alloys are among the most commonly used lightweight metallic materials which possess attractive mechanical and thermal properties. Machinability of this material possesses relative easiness compared to other metals. Machinability quantifies the machining performance, and may be defined by various criteria, such as tool life, surface finish, chip evacuation, material removal rate and machine-tool power (V. Songmene et. al, 2011). Pure aluminium possess relatively low mechanical properties which are improved by alloying the metal with other metals such as copper, manganese, silicon, magnesium, silicon, zinc, etc. Aluminium with magnesium and silicon as alloys are commercially designated as $\mathrm{Al} 6 \mathrm{xxx}$ series alloys. Among aluminium alloys Al 6061 exhibits excellent mechanical properties, corrosion resistance (Xuewu Lia,2015) and weldability (Omega Research, 2002) which finds the applications in aircraft, missiles and space, ground and marine transportation, screws, machine parts and architectural applications. Toh et. al. (2004) studied the surface integrity effects on turned 6061 and 6061-T6 aluminium alloys. Investigations on machining of 6061 aluminium alloy with minimum quantity of lubricant (MQL), dry and flooded lubricant conditions were made by Sreejith (2008). Machining effects were analysed with respect to the cutting forces, surface roughness of the machined work-piece and tool wear. It was found that MQL condition is good alternative to flooded coolant conditions. Authors concluded that properly employed MQL can replace the flooded coolant environment which is presently employed in most of the cutting/machining applications, thereby machining will be environmental friendly and improve the machinability characteristics. Mukesh Kumar Barua et. al. (2009) studied the effect of coated carbide tool on 6061-t4 aluminium. The effects of cutting parameters such as speed, depth of cut and cutting feed rate on the surface roughness was investigated by the authors and also regression model has been developed. Halil Demir et. al. (2009) studied the effect of artificial aging on the machinability of 6061 Al-alloy as-received, solution heat treated and solution heat treated under aged conditions. It was found that different aging times at $180^{\circ} \mathrm{C}$ and the cutting speed significantly affected the surface roughness of the machined surface. But, cutting forces were not significantly influenced by aging and cutting speed except for solution heat treated (SHT) work pieces having the lowest hardness. Optimization of cutting parameter was carried by Carmita (2013) to minimize the energy consumption in turning of AISI 6061 T6. Machine tools are responsible for environmental impacts owing to their energy consumption. Higher feed rate was found to minimize energy consumption but it led to higher surface roughness. Influence of cutting parameters on cutting force and surface finish was investigated by Rao et. al. (2013). Feed rate was found to have significant influence on cutting force as well as surface roughness. Depth of cut was found to have significant influence on cutting force, but has an insignificant influence on surface roughness. Authors also have developed the optimum combination of feed rate and depth of cut to reduce power consumption as well as to achieve the better surface finish. Vinod Mishra et. al. (2014) studied the effects of tool overhang on selection of machining parameters and surface finish. They found that too large and very small tool overhangs results in poor surface finish. Further, optimum range of tool overhang with minimum tool vibrations was established. 


\section{MATERIALS AND METHODS}

\subsection{Experimental Setup}

Figure 1 shows the experimental set up used in the present work. Turning experiments were conducted using CNC turning centre manufactured by ACE machine tools. The cutting tool used was silicon carbide insert tool. The process parameters considered in the present study are shown in the Table 1 . The levels of these parameters are chosen based on the pilot study conducted at various settings. Experiments were designed using Taguchi method to use the experimental resources optimally. Experimental design is done with $\mathrm{L}_{9}$ Taguchi orthogonal array. Experiments were conducted at various levels of the process parameters in as shown in the Table 2. Each trial is conducted in two types of test conditions. In the first condition machining is carried out without using coolant (called dry machining) and in second condition machining is carried by supplying coolant while machining. The average surface roughness $(\mathrm{Ra})$ obtained on the machined surface is measured using Taylor Habson Surtronic instrument. Table 2 also shows the corresponding $\mathrm{Ra}$ (micron) values obtained in each experimental condition as mentioned in the design. The experimental results were analyzed using analysis of variance (ANOVA) to estimate the relative effect of each process parameters.

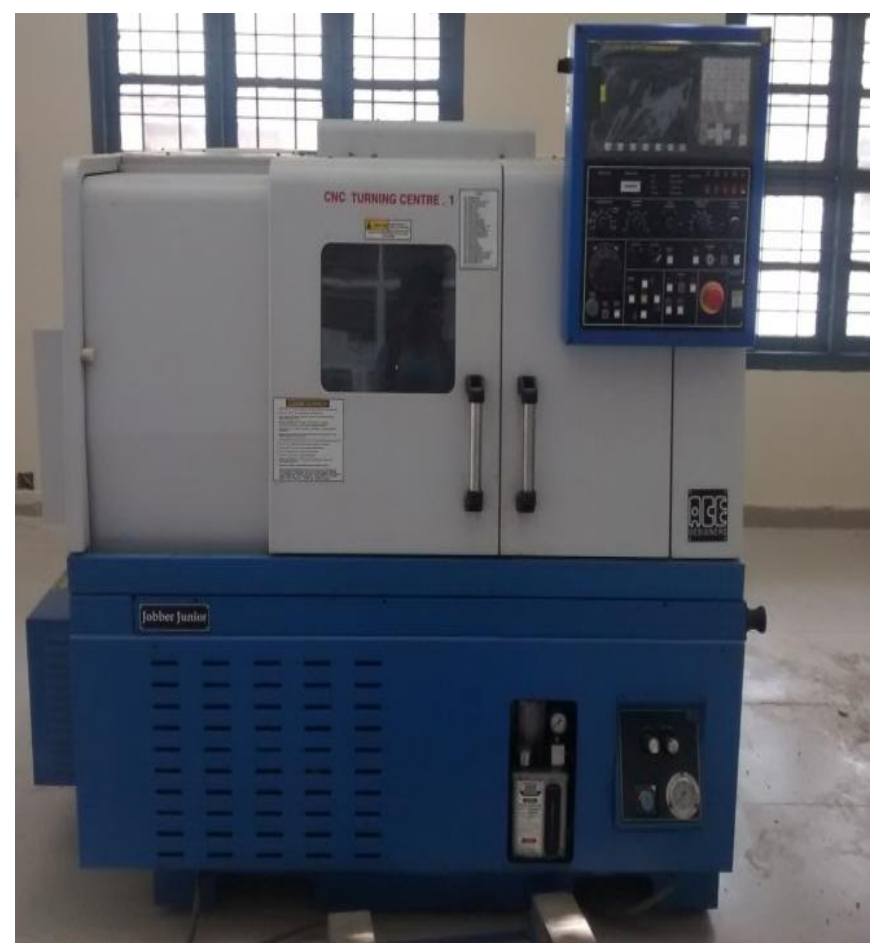

Fig. 1. Experimental set up

Table.1: Process Parameter and their Levels

\begin{tabular}{|l|l|l|l|l|}
\hline Factor/Level & & 1 & 2 & 3 \\
\hline Cutting Speed (m/min) & A & 308 & 369 & 429 \\
\hline Feed (mm/rev) & B & 0.05 & 0.1 & 0.15 \\
\hline Depth of Cut (mm) & C & 1 & 1.5 & 2 \\
\hline
\end{tabular}

Table.2: Experimental Plan and Average Results

\begin{tabular}{|l|l|l|l|l|l|l|}
\hline A & \multirow{2}{*}{$\mathrm{B}$} & \multirow{2}{*}{$\mathrm{C}$} & \multicolumn{2}{|l|}{ Without coolant } & \multicolumn{2}{l|}{ With coolant } \\
\cline { 4 - 7 } & & & $\mathrm{R}_{\mathrm{a} 1}$ & $\mathrm{R}_{\mathrm{a} 2}$ & $\mathrm{R}_{\mathrm{a} 1}$ & $\mathrm{R}_{\mathrm{a} 2}$ \\
\hline 308 & 0.05 & 1 & 1.40 & 1.27 & 0.7 & 1.01 \\
\hline 308 & 0.1 & 1.5 & 1.81 & 1.97 & 1.1 & 1.64 \\
\hline 308 & 0.15 & 2 & 2.98 & 2.92 & 2.77 & 2.8 \\
\hline 369 & 0.05 & 1.5 & 1.65 & 1.83 & 1.61 & 0.96 \\
\hline 369 & 0.1 & 2 & 1.77 & 1.46 & 1.91 & 0.83 \\
\hline 369 & 0.15 & 1 & 2.55 & 2.15 & 2.21 & 1.67 \\
\hline 429 & 0.05 & 2 & 1.44 & 1.21 & 1.01 & 0.94 \\
\hline 429 & 0.1 & 1 & 1.58 & 1.35 & 0.66 & 1.22 \\
\hline 429 & 0.15 & 1.5 & 2.03 & 2.20 & 1.56 & 1.73 \\
\hline
\end{tabular}

\section{RESULTS AND DISCUSSION}

\subsection{The Effect of Operating Parameters on Surface}

\section{Roughness}

The present work investigates the effect of operating parameters such as cutting speed, feed rate and depth of cut. Figure 2 and Figure 3 shows the main effects plots of surface roughness $\left(\mathrm{R}_{\mathrm{a}}\right)$ obtained while machining of sample work pieces in dry mode as well as when machining using coolant respectively.

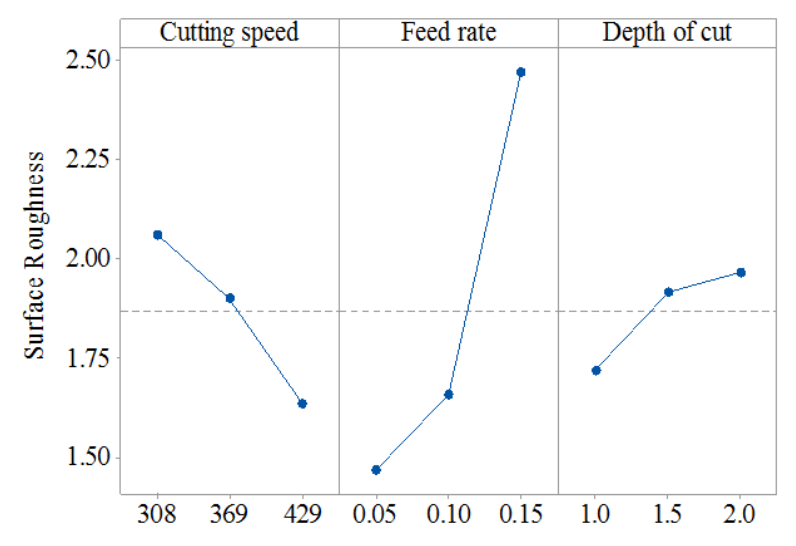

Fig. 2. Effect of operating parameters on surface roughness in dry machining

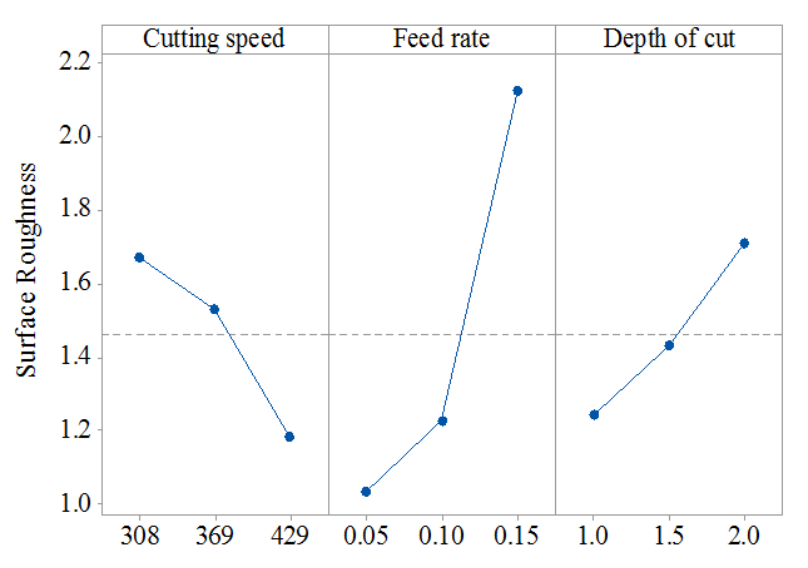

Fig. 3. Effect of operating parameters on surface roughness when machining with coolant 
It is seen from the Figure 2 and Figure 3 that the surface roughness decreases with increase in the cutting speed (spindle speed). The magnitude of decrease in surface roughness is more between level 2 and level 3 when compared level 1. Between level 1 and level 2, the cutting speed increases by $19.80 \%$ and the surface roughness decreases by $8.45 \%$. Between level 2 and level 3, the cutting speed increases by $16.26 \%$ resulting in decreasing of surface roughness by $14.67 \%$. It is observed that smoother cut surface is generated at higher cutting speeds. The surface roughness is found to decrease by $31.44 \%$ for increase in cutting speed by $39.29 \%$. At higher cutting speeds more strain energy is available for the work-piece which leads to continuous and easy removal of the material. Hence the $R_{a}$ values are found to decrease with increase in cutting speed.

Further, it is observed from the main effect plots shown in Figure 2 and Figure 3 that increase in feed rate leads to increase in surface roughness. Between level 1 and level 2, the surface roughness is found to increase by $11.80 \%$ compared $48 \%$ between level 2 and level 3. This is due to the fact that at higher feed rates, the axial movement of the cutting tool is large which results in shifting of the tool to new position on the work surface without completely removing the material. This creates rough surfaces on the material. In addition, the effect of depth of cut on surface roughness is also shown in the same figures. It is seen that, increase in depth of cut increases the surface roughness by $12.04 \%$ (level 1 to level 2) and $2.68 \%$ (level 2 to level 3). Higher depth of cut creates higher thrust force on the cutting tool which push the tool radially outward. As a result the tool will be released from the work-piece causing vibrations which results in increase in surface roughness. The relative effects of chosen process parameters are determined by ANOVA shown in Table 3 and Table 4.

Table.3: ANOVA Machining Without Coolant

\begin{tabular}{|l|l|c|c|l|}
\hline Source & DF & SS & MS & \% C \\
\hline A & 2 & 0.2921 & 0.14603 & 13.82 \\
\hline B & 2 & 1.5262 & 0.76310 & 72.22 \\
\hline C & 2 & 0.1079 & 0.05393 & 5.10 \\
\hline Error & 2 & 0.1871 & 0.09353 & \\
\hline Total & 8 & 2.1132 & & \\
\hline
\end{tabular}

Table.4: ANOVA for Machining With Coolant

\begin{tabular}{|l|c|c|c|l|}
\hline Source & DF & SS & MS & \% C \\
\hline A & 2 & 0.4355 & 0.21774 & 14.37 \\
\hline B & 2 & 2.1564 & 1.07822 & 71.18 \\
\hline C & 2 & 0.1867 & 0.09337 & 6.16 \\
\hline Error & 2 & 0.2506 & 0.12530 & \\
\hline Total & 8 & 3.0292 & & \\
\hline
\end{tabular}

Based on the Means Square (MS) values of surface roughness obtained due to variations in different process parameters, the percentage contribution (\% C) of each process parameter is determined. From the ANOVA tables it can be inferred that feed rate is most influential process parameters affecting the surface roughness followed by cutting speed and depth of cut respectively.

\subsection{Comparative Analysis of Surface Roughness}

\section{Generated While Machining Without Coolant and With Coolant Supply}

The mean surface roughness obtained at different levels of the each process parameters in dry machining i.e., without supply of coolant as well as machining with coolant is calculated and is shown in Table 5. From the table it is observed that components that were machined with supply of coolant exhibited better surface finish. The coolant used in the turning operation reduces the thermal stresses. Also, chips are washed from the cutting surface of the work-piece. Thus prevents the sticking of tiny chips on-to the work-piece. Hence the surface finish is found to be improved. The percentage reduction (improvement) in surface roughness at each level of different process parameters is shown in Table 6. From Table 5, it is seen that lowest surface roughness is produced at cutting speed $308 \mathrm{~m} / \mathrm{min}$ (level 3), feed rate 0.05 $\mathrm{mm} / \mathrm{rev}$ (level 1) and depth of cut $1 \mathrm{~mm}$ (level 1). Hence this $\left(\mathrm{A}_{3} \mathrm{~B}_{1} \mathrm{C}_{1}\right)$ can be considered as optimum settings for turning parameters. Confirmation experiments were conducted in the above settings.

Table.5: Average Surface Roughness at Deferent Levels of Process Parameters

\begin{tabular}{|c|c|c|c|c|c|c|}
\hline \multicolumn{7}{|c|}{ Machining in dry } \\
\hline Level & A & B & C & A & B & C \\
\hline 1 & 2.01 & 1.44 & 1.66 & 1.65 & 0.96 & 1.22 \\
\hline 2 & 1.84 & 1.61 & 1.86 & 1.44 & 1.15 & 1.40 \\
\hline 3 & 1.57 & 2.38 & 1.91 & 1.11 & 2.08 & 1.57 \\
\hline & 0.43 & 0.94 & 0.25 & 0.53 & 1.12 & 0.35 \\
\hline
\end{tabular}

Table.6: Percentage Improvement in Surface Finish

\begin{tabular}{|l|l|l|l|}
\hline Level & A & B & C \\
\hline 1 & $17.91 \%$ & $50 \%$ & $36.07 \%$ \\
\hline 2 & $21.74 \%$ & $40 \%$ & $32.86 \%$ \\
\hline 3 & $29.30 \%$ & $14.42 \%$ & $21.66 \%$ \\
\hline
\end{tabular}

\section{CONCLUSION}

Following conclusions are drawn from the present experimental work.

- It is observed that the feed rate is most influential process parameters that influence surface roughness while turning of Aluminum 6061 followed by cutting speed and depth of cut.

- It is observed that smoother cut surface is generated at higher cutting speeds. The surface roughness is found to decrease by $31.44 \%$ for increase in cutting speed by $39.29 \%$. Increase in depth of cut increases the surface roughness by $12.04 \%$ (level 1 to level 2) and $2.68 \%$ (level 2 to level 3). Increase in feed rate leads to increase in surface roughness by $11.80 \%$ to $48 \%$ at different settings of process parameters.

- Comparative analysis of machining of component in conditions such as without using coolant and by using coolant shows that component that were machined with coolant exhibited lower surface roughness. 


\section{REFERENCES}

[1] Carmita Camposeco-Negrete, 2013, Optimization of cutting parameters for minimizing energy consumption in turning of AISI 6061 T6 using Taguchi methodology and ANOVA, Journal of Cleaner Production, Volume 53, 15 pp. $195-203$

[2] Halil Demir, Süleyman Gündüz, 2009, The effects of aging on machinability of 6061 aluminium alloy, Materials and Design vol 30, 1480-1483

[3] Mukesh Kumar Barua, Anbuudayasankar, Measurement of surface roughness through RSM: effect of coated carbide tool on 6061-t4 aluminium, International Journal of Enterprise Network Management, Volume 4, Issue 2, DOI: 10.1504/IJENM.2010.037931

[4] Paneerselvam, 2012, Design and analysis of experiments, PHI learning private ltd., ISBN 978-81203-4499-0

[5] C. J. Rao, D. Nageswara Rao, P. Srihari, 2013, Influence of cutting parameters on cutting force and surface finish in turning operation, International Conference On DESIGN AND MANUFACTURING, IConDM 2013, Procedia Engineering 64, pp. 1405 1415

[6] P.S. Sreejith, Machining of 6061 aluminium alloy with MQL, dry and flooded lubricant conditions, 2008, Materials Letters, Volume 62, Issue 2, Pp.276-278

[7] V. Songmene, R. Khettabi, I. Zaghbani, J. Kouam, and A. Djebara, 2011, Machining and Machinability of Aluminum Alloys, Aluminium Alloys, Theory and Applications, Tibor Kvackaj (Ed.), ISBN: 978-953-307244-9

[8] Vinod Mishraa, Gufran S. Khanb, K.D. Chattopadhyaya, Keshva Nanda, RamaGopal V. Sarepakaa, 2014, Effects of tool overhang on selection of machining parameters and surface finish during diamond turning, Measurement, Volume 55, Pp. 353361

[9] Xuewu Lia, Qiaoxin Zhanga, Zheng Guo, Tian Shi, Jingui Yu, Mingkai Tang, Xingjiu Huang, 2015, Fabrication of superhydrophobic surface with improved corrosion inhibition on 6061 aluminum alloy substrate, Applied Surface Science, Volume 342, pp. 76-83. 